DOI: https://doi.org/10.47405/mjssh.v6i9.1035

\begin{tabular}{|c|c|}
\hline & Malaysian Journal of Social Sciences and Humanities (MJSSH) \\
\hline Malaysian Journal of & Volume 6, Issue 9, September 2021 \\
\hline (MJ-SSH) & e-ISSN : 2504-8562 \\
\hline & $\begin{array}{l}\text { Journal home page: } \\
\text { www.msocialsciences.com }\end{array}$ \\
\hline
\end{tabular}

\title{
Keberkesanan Penggunaan Perisian GeoGebra dalam Pembelajaran Fungsi dan Graf Terhadap Pencapaian Pelajar Matrikulasi Jurusan Perakaunan
}

\author{
Norazliana Mohmad Kamal' ${ }^{1}$, Siti Mistima Maat ${ }^{1}$ \\ ${ }^{1}$ Fakulti Pendidikan, Universiti Kebangsaan Malaysia (UKM)
}

Correspondence: Norazliana Mohmad Kamal (norazlianakamal@gmail.com)

\begin{abstract}
Abstrak
Kajian ini dijalankan untuk mengenal pasti keberkesanan penggunaan perisian GeoGebra dalam pembelajaran fungsi dan graf terhadap pencapaian pelajar matrikulasi jurusan perakaunan. Seramai 92 orang pelajar jurusan perakaunan Kolej Matrikulasi Melaka yang terlibat dan terdiri daripada kumpulan eksperimen $(n=47)$ dan kumpulan kawalan $(n=45)$. Instrumen kajian merupakan kertas ujian pra, kertas ujian pasca dan borang soal selidik yang telah diadaptasi. Data dianalisis menggunakan statistik deskriptif, ujian t dua sampel tidak bersandar dan ujian ANOVA satu hala. Dapatan kajian mendapati bahawa tidak terdapat perbezaan yang signifikan pada min skor ujian pra antara pelajar daripada kumpulan eksperimen dengan kumpulan kawalan; $\mathrm{t}(90)=-0.722 ; \mathrm{p}>0.05$. Walau bagaimanapun terdapat perbezaan yang signifikan pada min skor ujian pasca antara pelajar daripada kumpulan eksperimen dengan pelajar daripada kumpulan kawalan $\mathrm{t}(90)=2.100$; $\mathrm{p}<0.05$. Dapatan ujian ANOVA sehala menunjukkan terdapat perbezaan yang signifikan antara skor ujian pasca antara ketiga-tiga kumpulan prestasi pelajar iaitu prestasi rendah, sederhana dan tinggi; $F(2,44)=5.691 ; \mathrm{p}<0.05, \eta 2=0.206$. Analisis pos hoc Tukey turut dijalankan dan didapati terdapat perbezaan signifikan antara pelajar berprestasi rendah dan pelajar berprestasi tinggi. Namun, tidak terdapat perbezaan yang signifikan antara pelajar berprestasi sederhana dengan dua kumpulan yang lain. Analisis deskriptif menunjukkan tahap keberkesanan penggunaan perisian matematik (GeoGebra) dalam pengajaran dan pembelajaran topik fungsi dan graf adalah tinggi iaitu 3.96. Melalui dapatan kajian, dapat dirumuskan bahawa penggunaan perisian GeoGebra adalah lebih baik berbanding pengajaran menggunakan kaedah konvensional dan pencapaian pelajar meningkat selepas penggunaan perisian GeoGebra. Kesimpulannya, pelajar berprestasi tinggi mendapat skor yang lebih tinggi berbanding pelajar berprestasi rendah selepas penggunaan perisian GeoGebra.
\end{abstract}

Kata kunci: fungsi dan graf, GeoGebra, keberkesanan, pencapaian, pelajar

\section{The Effectiveness of Using GeoGebra Software in Learning Functions and Graphs Towards the Achievement of Accounting Matriculation Students}

\begin{abstract}
This study was conducted to identify the effectiveness of using GeoGebra software in learning functions and graphs towards the achievement of matriculation students majoring in accounting. A total of 92 students majoring in accounting at Malacca Matriculation College were involved and consisted of the experimental group $(n=47)$ and the control group $(n=45)$. The research instruments are pre-test papers, post-test papers and questionnaires that have been adapted. Data were analyzed using descriptive statistics, two-sample independent $t$ test and one-way ANOVA test. The findings of the
\end{abstract}


study found that there was no significant difference in the mean of pre-test scores between students from the experimental group with the control group; $t(90)=-0.722 ; p>0.05$. However there was a significant difference in the mean of the post-test scores between students from the experimental group with students from the control group $\mathrm{t}(90)=2.100 ; \mathrm{p}<0.05$. The findings of one-way ANOVA test showed that there was a significant difference between the post-test scores between the three groups of student performance namely low, medium and high performance; $F(2.44)=5.691 ; p<0.05, \eta 2=0.206$. Tukey's post hoc analysis was also conducted and it was found that there were significant differences between low-achieving students and high-achieving students. However, there was no significant difference between moderate-achieving students with the other two groups. Descriptive analysis shows that the level of effectiveness of using mathematical software (GeoGebra) in teaching and learning the topic of functions and graphs is high at 3.96. Through the findings of the study, it can be concluded that the use of GeoGebra software is better than teaching using conventional methods and student achievement increases after the use of GeoGebra software. In conclusion, high-performing students got higher scores than low-performing students after the use of GeoGebra software.

Keywords: functions and graphs, GeoGebra, effectiveness, achievement, students

\section{Pengenalan}

Kemajuan teknologi yang berkembang pesat dan meluas di serata dunia telah mencetuskan pelbagai perubahan dalam kehidupan masyarakat pada era ini, terutamanya dari segi cara pembelajaran (Mudaly \& Fletcher, 2019). Ini selari dengan aspirasi Kementerian Pendidikan Malaysia (KPM) untuk menyediakan pelajar yang berkemahiran dan berpengetahuan agar dapat belajar dengan efektif dan meneroka dunia luar yang semakin global dan digital (Pelan Pembangunan Pendidikan Malaysia 20132025). Melalui pengintegrasian teknologi dalam pendidikan, pelajar boleh membina pengetahuannya sendiri, membuat visualisasi serta membuktikan ketepatan maklumat yang dikemukakan di dalam kelas (Shabiralyani et al., 2015). Justeru, penggunaan teknologi terkini sangat digalakkan kerana pelajar dapat meningkatkan kemahiran visualisasi, pemahaman konsep serta meneroka idea matematik yang abstrak (Rohaidah et al., 2016). Ini disokong oleh Effandi et al. (2007) yang menyatakan bahawa pengajaran dan pembelajaran matematik yang melaksanakan teknologi dapat membantu pelajar memahami matematik serta memberi makna kepada mereka. Terdapat pelbagai pendekatan teknologi berbentuk perisian matematik yang boleh diaplikasikan oleh para pendidik, di antaranya adalah GeoGebra, Geometer's Sketchpad dan Mathematica (Nazihatulhasanah \& Nurbiha, 2015).

GeoGebra merupakan suatu perisian matematik dinamik yang interaktif dan boleh dijadikan suatu pendekatan metodologi moden dalam pengajaran matematik. Melalui penggunaan perisian GeoGebra ini, guru-guru dapat menyediakan persekitaran pembelajaran matematik yang mengasimilasikan perwakilan matematik dengan cara yang berbeza. Joki'c dan Taka`ci (2020) berpendapat bahawa pengajaran yang menggunakan pendekatan tradisional ada kalanya lebih tertumpu pada perwakilan algebra. Justeru, pelajar melihat perwakilan grafik dan algebra sebagai entiti yang berasingan. Oleh sebab itu, pelajar sukar untuk membuat visualisasi dan melakar graf apabila sesuatu fungsi diberikan.

Di Malaysia, konsep fungsi dan sifatnya mula diperkenalkan secara khusus dalam mata pelajaran Matematik Tambahan Tingkatan Empat. Ini diteruskan dalam mata pelajaran Matematik Tingkatan Lima di mana pelajar terdedah kepada bentuk dan sifat graf bagi fungsi linear, kuadratik dan kubik. Pada peringkat matrikulasi, pelajar akan diperkenalkan lagi dengan beberapa fungsi graf yang lain. Namun, terdapat sebilangan pelajar yang masih belum menguasai konsep asas untuk melakar graf fungsi linear, kuadratik dan kubik. Masalah penguasaan konsep asas melakar graf ini bukan sahaja berlaku di Malaysia malah turut dialami di negara lain iaitu di Afrika Selatan seperti yang dikaji oleh Mudaly dan Fletcher (2019) dan juga di negara Turki berdasarkan kajian yang dilakukan oleh Ovez (2018). Selain tidak menguasai konsep asas, pelajar-pelajar turut menghadapi masalah untuk membuat visualisasi (Murni et al., 2017). Casey dan Fell (2019) menyatakan bahawa terdapat perkaitan antara kemahiran visualisasi yang baik dengan pencapaian pelajar dalam matematik. Manakala, Mushipe dan Ogbonnaya (2019) berpendapat bahawa pencapaian yang lemah dalam matematik boleh dikaitkan 
dengan amalan pengajaran guru kerana ramai pelajar tidak gemar belajar matematik kerana mereka merasakan tidak menarik dan membosankan.

Konsep matematik yang abstrak bagi sesetengah topik menyebabkan pelajar sukar untuk menguasai sesuatu topik dengan mendalam (Saidatuna \& Rosseni, 2016). Khalil et al. (2019) dalam kajiannya menyatakan bahawa dalam pembelajaran matematik di peringkat yang lebih tinggi, pemahaman konsep abstrak adalah sangat penting dan merupakan salah satu objektif utama pendidikan matematik. Namun begitu, pelajar di matrikulasi melihat topik fungsi dan graf terlalu sukar kerana kelemahan dalam kemahiran visualisasi di samping konsep asas yang tidak kukuh serta tidak memahami konsep abstrak yang terdapat dalam topik ini. Menurut Shin dan Ling (2017), pelajar-pelajar di matrikulasi menghadapi masalah dalam menyelesaikan soalan-soalan yang melibatkan fungsi dan graf. Sehubungan itu, kajian ini dilakukan untuk menentukan keberkesanan penggunaan perisian GeoGebra sebagai alternatif untuk membantu pelajar dalam memahami topik fungsi dan graf dengan lebih mendalam. Pengkaji dapati kebanyakan kajian yang dijalankan tertumpu kepada satu jenis fungsi graf sahaja, antaranya adalah fungsi linear (Soots \& Shafer, 2018; Joshi \& Singh, 2020), fungsi kuadratik (Ovez, 2018; Fatahillah et al., 2020) atau fungsi nilai mutlak (Gono, 2016; Widjajanti, 2019). Maka, dengan sebab itu, kajian ini bukan hanya tertumpu kepada satu jenis fungsi sahaja, sebaliknya, beberapa jenis fungsi graf yang lain iaitu fungsi linear, fungsi kuadratik, fungsi kubik, fungsi punca kuasa dua, fungsi nilai mutlak dan fungsi cebis demi cebis.

\section{Objektif Kajian}

i. Menentukan perbezaan min skor ujian pra dalam penyelesaian masalah fungsi dan graf antara kumpulan eksperimen dengan kumpulan kawalan sebelum penggunaan perisian GeoGebra.

ii. Menentukan perbezaan min skor ujian pasca dalam penyelesaian masalah fungsi dan graf antara kumpulan eksperimen dengan kumpulan kawalan selepas penggunaan perisian GeoGebra.

iii. Menentukan perbezaan min skor ujian pasca berdasarkan kategori pelajar kumpulan eksperimen dalam penyelesaian masalah fungsi dan graf selepas penggunaan perisian GeoGebra.

iv. Mengenal pasti tahap keberkesanan penggunaan perisian matematik (GeoGebra) dalam pengajaran dan pembelajaran topik fungsi dan graf.

\section{Hipotesis Kajian}

Hipotesis Nol 1: Tidak terdapat perbezaan yang signifikan min skor ujian pra dalam penyelesaian masalah fungsi dan graf antara kumpulan eksperimen dengan kumpulan kawalan sebelum penggunaan perisian GeoGebra.

Hipotesis Nol 2: Tidak terdapat perbezaan yang signifikan min skor ujian pasca dalam penyelesaian masalah fungsi dan graf antara kumpulan eksperimen dengan kumpulan kawalan selepas penggunaan perisian GeoGebra.

Hipotesis Nol 3: Tidak terdapat perbezaan yang signifikan min skor ujian pasca berdasarkan kategori pelajar kumpulan eksperimen selepas penggunaan perisian GeoGebra.

\section{Sorotan Literatur}

Pada era serba teknologi ini, terdapat pelbagai perisian matematik yang boleh diintegrasikan oleh guru dalam menyampaikan ilmu. Berdasarkan kajian Nazihatulhasanah dan Nurbiha (2015), di antara perisian yang sesuai digunakan untuk pengajaran dan pembelajaran matematik adalah GeoGebra, Geometer's Sketchpad dan Mathematica. GeoGebra merupakan satu perisian matematik dinamik yang 
sesuai digunakan bermula dari peringkat rendah hingga ke peringkat universiti. Menurut Gono (2016), istilah perisian matematik dinamik ini adalah merujuk kepada gabungan perisian geometri dinamik (Dynamic Geometry Software, DGS) dan sistem komputer algebra (Computer Algebra Systems, CAS). Fungsi DGS lebih tertumpu kepada hubungan antara titik, garis dan bulatan seperti perisian Geometer's Sketchpad dan Cabri Geometry. Manakala, CAS berfokus kepada memanipulasi ungkapan dan simbol contohnya perisian Maple, Autograph dan Derive. Ini bermakna, perisian GeoGebra menggabungkan kedua-dua fungsi tersebut iaitu DGS dan CAS dan penggunaannya meliputi pelbagai cabang bidang dalam matematik. Perisian GeoGebra dicipta oleh Markus Hohenwarter pada tahun 2001 dan boleh dilayari oleh pengguna di laman web http://www.geogebra.org bermula pada tahun 2002. Menurut Furner dan Yahya (2020), pengguna GeoGebra terdiri daripada pelbagai negara dan kini diterjemahkan ke dalam 55 bahasa. Ciri utama GeoGebra adalah jelas dan mudah untuk diterokai oleh pengguna. Pergerakan objek yang dinamik berdasarkan sintaks matematik yang dimasukkan, membolehkan pengguna memahami konsep matematik yang terlibat (Priwontoro \& Fahmi, 2019).

GeoGebra merupakan perisian percuma yang mesra pengguna dan mudah untuk diterokai oleh pelajar (Mushipe \& Ogbonnaya, 2019). Ini turut disokong oleh Rohaidah et al. (2016) yang menyatakan perisian ini lebih mudah untuk digunakan berbanding dengan perisian Mathematica dan Maple yang memerlukan kemahiran dalam pengaturcaraan dan pengekodan. Pelajar turut mudah untuk mengakses kerana pelajar boleh memuat turun GeoGebra berasaskan Android serta boleh menggunakannya tanpa talian internet selepas memuat turun aplikasi berkenaan. Menurut Septian et al. (2020), GeoGebra boleh meningkatkan keupayaan pemikiran kreatif matematik pelajar. Manakala, Ovez (2018) pula menyatakan bahawa GeoGebra mendorong pelajar ke arah pembelajaran penemuan. Selain itu, guru menjadi lebih kreatif dalam merancang pengajaran agar penyampaian sesuatu pelajaran lebih efektif, serta melibatkan pembelajaran dua hala (Hutkemri \& Effandi, 2012).

Pengajaran dan pembelajaran dalam matematik bukan hanya bergantung kepada teori semata-mata sebaliknya kepelbagaian pendekatan kaedah pengajaran perlu diamalkan untuk mewujudkan rasa minat pelajar terhadap subjek matematik. Berdasarkan kajian-kajian lepas, terdapat beberapa impak yang positif selepas penggunaan perisian GeoGebra diaplikasikan di dalam kelas antaranya adalah pembelajaran lebih menyeronokkan serta meningkatkan motivasi pelajar (Leong, 2015). Selain itu, pembelajaran kendiri dapat diwujudkan (Mudaly \& Fletcher, 2016), kemahiran komunikasi menjadi lebih baik (Kusumah et al., 2020), kemahiran visualisasi meningkat (Nobre et al., 2016) dan pencapaian pelajar juga turut meningkat (Otieno et al., 2017). Melalui penggunaan GeoGebra, pelajar berasa teruja dengan pendekatan penerokaan kendiri berbanding pendekatan berpusatkan guru. Ini turut disokong oleh kajian Nazihatulhasanah dan Nurbiha (2015) serta Mudaly dan Fletcher (2019), di mana pelajar seronok menggunakan perisian GeoGebra dan sesi pembelajaran interaktif dapat diwujudkan. Sehubungan itu, guru mendapat alternatif baru untuk menyalurkan ilmu dan ini menggalakkan para pendidik untuk lebih berinovasi dalam pengajaran dan pembelajaran (Saidatuna \& Rosseni, 2016).

Dalam pembelajaran matematik, pemahaman konsep yang abstrak sangat penting dan pelajar perlu mahir membuat visualisasi untuk menyelesaikan soalan-soalan matematik terutamanya yang melibatkan fungsi, geometri, penjelmaan, kebarangkalian dan lain-lain. Berdasarkan kajian Leong (2015), penggunaan GeoGebra membolehkan pelajar menggambarkan bentuk yang terhasil ketika menjawab soalan combined transformation. Rohaidah et al. (2016) pula menyatakan di dalam kajiannya bahawa GeoGebra Teaching Strategy (GTS) membantu pelajar untuk memahami topik Circle III dengan lebih jelas. Selain itu pembelajaran Shape and Space membolehkan pelajar menghasilkan kerja penyelesaian dengan bukti yang kritikal, kreatif dan inovatif (Khor \& Ruzlan, 2017). Selain meningkatkan kemahiran visualisasi pelajar, pencapaian pelajar dalam topik-topik tertentu dalam matematik turut meningkat. Ini dibuktikan oleh kajian Ovez (2018) bahawa kumpulan eksperimen mampu untuk menghubungkaitkan antara ungkapan algebra dan graf serta berjaya mentafsirkannya. GeoGebra membantu pelajar untuk menganalisis kesan perubahan parameter pada fungsi graf. Manakala kajian Muhammad Khalil et al. (2019) pula mendapati bahawa GeoGebra adalah alat bantu mengajar terbaik dalam membangunkan pemikiran matematik pelajar gred 12 dalam subjek geometri analitik sama ada pelajar itu berpencapaian tinggi atau rendah. Berdasarkan kajian Rohaidah et al. (2016), perisian GeoGebra boleh membantu guru mewujudkan persekitaran pembelajaran yang menyeronokkan kerana pelajar dapat meneroka konsep matematik dengan cara yang berbeza 
berbanding dengan kaedah konvensional. Dahal et al. (2019) pula menyatakan bahawa pengintegrasian GeoGebra dapat membantu mengubah sesuatu konsep matematik yang abstrak menjadi konkrit dan ia juga dapat membantu pelajar dalam kemahiran visualisasi.

GeoGebra juga dapat meningkatkan kefahaman pelajar tentang fungsi, graf dan ciri-cirinya dengan cara yang berbeza (Birgin \& Acar, 2020). Perisian ini memberi guru dan pelajar alat teknologi baru percuma, kaedah baru menggunakan teknologi dengan alat bantu visual untuk membantu pelajar berinteraksi dengan konsep matematik secara individu atau kumpulan di dalam kelas, atau di rumah, atau di mana-mana tempat yang sesuai mengikut keperluan para guru dan pelajar (Ogan \& Ibobo, 2018). Carnaúba dan Blikstein (2020) berpendapat bahawa GeoGebra adalah alat yang fleksibel dan membolehkan guru merancang pengalaman pembelajaran yang sangat berbeza. Maka, pengkaji berpendapat bahawa perisian GeoGebra sesuai digunakan sebagai medium untuk membantu pelajar memahami topik fungsi dan graf dengan baik kerana topik ini memerlukan pelajar untuk memahami konsep fungsi dan graf, seterusnya, dapat memvisualisasi perwakilan grafik berdasarkan fungsi yang diberikan dan memahami konsep abstrak yang terdapat pada fungsi dan graf.

\section{Metod Kajian}

\section{Reka Bentuk Kajian}

Reka bentuk yang digunakan dalam kajian ini adalah kuasi eksperimen. Reka bentuk kuasi eksperimen tidak melibatkan pemilihan sampel secara rawak (Mohd. Majid, 2005). Sehubungan itu, reka bentuk ini dipilih disebabkan terdapat kesukaran untuk memilih responden secara rawak di kolej matrikulasi. Responden ini dibahagikan kepada dua kumpulan, iaitu kumpulan eksperimen dan kumpulan kawalan. Menurut Johnson dan Christensen (2014), reka bentuk yang terdiri daripada kumpulan eksperimen dan kumpulan kawalan yang tidak dirawat dan tidak setara perlu diberikan ujian pra dan ujian pasca.

Jadual 1 menunjukkan reka bentuk ujian-pra ujian-pasca kumpulan tidak setara. Kumpulan yang terlibat ini diberikan ujian pra, $\mathrm{O}_{1}$ sebelum proses pengajaran dilaksanakan. Semasa proses pengajaran, kumpulan eksperimen didedahkan dengan penggunaan perisian GeoGebra, G manakala kumpulan kawalan menggunakan kaedah pengajaran konvensional, $\mathrm{K}$ iaitu proses pengajaran berpusatkan guru dan pelajar tidak didedahkan dengan perisian GeoGebra. Selepas proses pengajaran, kedua-dua kumpulan diberikan ujian pasca, $\mathrm{O}_{2}$. Pemilihan dan pengagihan kumpulan-kumpulan tersebut tidak dibuat secara rawak kerana setiap kolej matrikulasi telah menetapkan kemasukan pelajar ke dalam kelas yang tertentu. Kemasukan pelajar adalah mengikut kelas yang spesifik berdasarkan garis panduan kolej, maka pemilihan pelajar secara rawak adalah sukar (Miller et al., 2020).

Jadual 1: Reka bentuk ujian pra dan ujian pasca kumpulan tidak setara

\begin{tabular}{lccc}
\hline Kumpulan & Ujian Pra & Proses Pengajaran & Ujian Pasca \\
\hline Eksperimen & $\mathrm{O}_{1}$ & Penggunaan Perisian GeoGebra, G & $\mathrm{O}_{2}$ \\
Kawalan & $\mathrm{O}_{1}$ & Kaedah Pengajaran Konvensional, K & $\mathrm{O}_{2}$ \\
\hline
\end{tabular}

Bagi menangani isu mengenai pemilihan sampel, pengkaji menggunakan pasangan kumpulan responden yang mempunyai ciri-ciri yang hampir setara sebagai kumpulan eksperimen dan kumpulan kawalan. Hal ini disebabkan kemungkinan dapatan kajian boleh dipengaruhi oleh ciri-ciri yang dimiliki oleh pelajar apabila melakukan kuasi eksperimen (Brown et al., 2020). Walau bagaimanapun, ini dapat ditangani kerana prestasi pelajar bagi setiap kelas di peringkat matrikulasi dalam subjek Matematik Tambahan adalah seimbang berdasarkan keputusan Sijil Pelajaran Malaysia (SPM) masing-masing. Ini bermakna, setiap kelas terdiri daripada pelajar yang berpencapaian rendah, sederhana dan tinggi. 


\section{Responden Kajian}

Responden kajian terdiri daripada pelajar matrikulasi jurusan perakaunan sesi 2020/2021 dan dipilih berdasarkan kelas yang sedia ada kerana responden kajian tidak dapat dipilih secara rawak (Johnson \& Christensen, 2014). Pemilihan pelajar dibuat pada sesi ini adalah kerana setiap sesi pelajar menghadapi masalah dalam menyelesaikan soalan-soalan yang melibatkan fungsi dan graf (Shin \& Ling, 2017). Seramai 92 orang pelajar terbabit dalam kajian ini dan dibahagikan kepada dua kumpulan iaitu kumpulan eksperimen dan kumpulan kawalan. Kumpulan eksperimen terdiri daripada 47 orang pelajar yang melalui proses pengajaran berbantukan perisian GeoGebra. Manakala kumpulan kawalan yang tidak didedahkan dengan perisian GeoGebra adalah seramai 45 orang pelajar. Saiz sampel diambil dengan merujuk saranan Mohd. Majid (2005); pengkaji digalakkan menggunakan saiz sampel melebihi 30 unit kerana andaian taburan normal biasanya dipenuhi dan pertambahan saiz sampel ini akan lebih mewakili populasi. Walau bagaimanapun, menurut Moreno-Guerrero et al. (2020), saiz sampel bukan faktor penentu dalam kajian yang memberi tumpuan kepada aplikasi kaedah pedagogi.

Jadual 2 : Data demografi responden kajian

\begin{tabular}{llcc}
\hline Kumpulan & Jantina & $\mathbf{N}$ & $\mathbf{\%}$ \\
\hline Eksperimen & Lelaki & 7 & 14.89 \\
& Perempuan & 40 & 85.11 \\
& Jumlah & 47 & 100.00 \\
\hline Kawalan & Lelaki & 6 & 13.33 \\
& Perempuan & 39 & 86.67 \\
& Jumlah & 45 & 100.00 \\
\hline
\end{tabular}

\section{Instrumen Kajian}

Terdapat dua instrumen yang digunakan dalam kajian ini iaitu kertas ujian pra dan ujian pasca serta borang soal selidik. Kertas ujian pra dan ujian pasca adalah soalan yang berkait dengan fungsi dan graf. Tujuan ujian ini adalah untuk menentukan kefahaman dan kebolehan pelajar untuk membuat visualisasi serta pencapaian pelajar dalam topik fungsi dan graf sebelum dan selepas perisian GeoGebra diperkenalkan. Tajuk fungsi dan graf ini dipilih oleh pengkaji kerana kebanyakan pelajar merasakan tajuk ini agak sukar untuk dipelajari terutamanya dalam melakar graf. Soalan-soalan merangkumi graf fungsi linear, kuadratik, kubik, nilai mutlak, punca kuasa dan cebis demi cebis. Pembinaan soalan ujian adalah berdasarkan contoh-contoh soalan yang diambil dari koleksi soalan peperiksaan lepas. Bagi memastikan soalan-soalan ujian pra dan ujian pasca menepati keperluan spesifikasi kurikulum matrikulasi, pengkaji merujuk kepada dua pensyarah matrikulasi yang merupakan pakar mata pelajaran (Subject Matter Expert, SME) untuk kesahan muka dan kandungan.

Soal selidik yang digunakan dalam kajian ini diadaptasikan daripada Pfeiffer (2017) dan diedarkan kepada responden daripada kumpulan eksperimen selepas selesai sesi pengajaran. Terdapat tiga konstruk dalam soal selidik ini di mana konstruk yang pertama, pengajaran dan pembelajaran matematik yang mengandungi tujuh item. Konstruk yang kedua iaitu penggunaan perisian matematik dalam pengajaran matematik pula mengandungi tiga item. Manakala, empat item terdapat di dalam konstruk yang ketiga iaitu keberkesanan GeoGebra sebagai bahan bantu mengajar dalam topik fungsi dan graf. Bagi menilai instrumen soal selidik, pemilihan panel pakar adalah terdiri daripada seorang pensyarah matrikulasi yang berpengalaman lebih daripada 15 tahun dalam mengajar mata pelajaran matematik serta mempunyai pengetahuan yang luas dalam bidang pendidikan (Hadjichambis \& Paraskeva-Hadjichambi, 2020). Panel pakar telah diberikan borang pengesahan instrumen kajian untuk menilai dan memastikan isi kandungan instrumen bersesuaian dan menepati matlamat kajian. Seterusnya, pengkaji akan mengumpulkan dan menganalisis keputusan yang diperolehi daripada penilaian yang telah dibuat oleh panel pakar. Dalam kajian ini, skala ordinal digunakan sebagai skala pengukuran. Berdasarkan Allanson dan Nortar (2020), susunan nilai kualiti sesuatu pemboleh ubah dapat digambarkan melalui skala ordinal. Selain itu, penskoran soal selidik juga dinilai menggunakan skala Likert lima mata seperti Jadual 3. 
DOI: https://doi.org/10.47405/mjssh.v6i9.1035

Jadual 3: Penskoran skala Likert lima mata

\begin{tabular}{lcc}
\hline Peringkat & Singkatan & Skor \\
\hline Sangat Tidak Setuju & STS & 1 \\
Tidak Setuju & TS & 2 \\
Kurang Setuju & KS & 3 \\
Setuju & S & 4 \\
Sangat Setuju & SS & 5 \\
\hline
\end{tabular}

\section{Penganalisisan Data}

Data dianalisis berdasarkan ujian pra, ujian pasca dan soal selidik yang telah dijawab oleh responden. Kesemua data yang telah dikumpul akan dianalisis dengan menggunakan perisian Statistical Package for Social Science (SPSS) Versi 26. Penetapan skala interpretasi bagi menentukan pengukuran skor min adalah seperti dalam Jadual 4. Skala interpretasi skor min ini adalah berpandukan skala yang telah digunakan oleh pengkaji lepas iaitu Abdul Halim et al. (2017).

Jadual 4: Interpretasi skor min bagi keberkesanan penggunaan perisian GeoGebra

\begin{tabular}{cc}
\hline Skor min & Interpretasi \\
\hline $1.00-2.33$ & Rendah \\
$2.34-3.67$ & Sederhana \\
$3.68-5.00$ & Tinggi \\
\hline
\end{tabular}

\section{Hasil Kajian}

Hipotesis Nol 1: Tidak terdapat perbezaan yang signifikan min skor ujian pra dalam penyelesaian masalah fungsi dan graf antara kumpulan eksperimen dengan kumpulan kawalan sebelum penggunaan perisian GeoGebra.

Hipotesis Nol 2: Tidak terdapat perbezaan yang signifikan min skor ujian pasca dalam penyelesaian masalah fungsi dan graf antara kumpulan eksperimen dengan kumpulan kawalan selepas penggunaan perisian GeoGebra.

Ujian parametrik iaitu ujian-t dua sampel tidak bersandar digunakan bagi menjawab hipotesis yang pertama dan kedua. Sebelum ujian tersebut digunakan, pengkaji terlebih dahulu telah menyemak sama ada andaian normaliti data dipenuhi. Jadual 5 menunjukkan dapatan bagi ujian normaliti. Menurut Nor Aishah et al. (2011), ujian normaliti Shapiro-Wilk digunakan bagi saiz sampel yang berada antara 3 hingga 50. Keputusan aras signifikan skor ujian pra dan ujian pasca bagi kedua-dua kumpulan menunjukkan $\mathrm{p}>0.05$, ini bermakna data bertaburan secara normal.

Jadual 5: Ujian normaliti data

\begin{tabular}{llcccccc}
\hline \multirow{2}{*}{ Kumpulan } & \multicolumn{2}{c}{ Kolmogorov-Smirnov } & \multicolumn{3}{c}{ Shapiro-Wilk } \\
\cline { 3 - 8 } & Statistik & df & Sig, p & Statistik & df & Sig, p \\
\hline \multirow{2}{*}{ Ujian pra } & Eksperimen & 0.114 & 47 & 0.161 & 0.961 & 47 & 0.116 \\
& Kawalan & 0.109 & 45 & 0.200 & 0.952 & 45 & 0.061 \\
\hline \multirow{2}{*}{ Ujian pasca } & Eksperimen & 0.103 & 47 & 0.200 & 0.964 & 47 & 0.162 \\
& Kawalan & 0.119 & 45 & 0.113 & 0.950 & 45 & 0.052 \\
\hline
\end{tabular}

Selain daripada ujian normaliti data, andaian bahawa varians adalah homogen juga perlu dipenuhi sebelum menggunakan ujian-t dua sampel tidak bersandar. Berdasarkan Jadual 6, didapati ujian Levene menunjukkan $\mathrm{p}>0.05$, maka andaian bahawa varians adalah homogen dipenuhi. 
DOI: https://doi.org/10.47405/mjssh.v6i9.1035

Jadual 6: Ujian kehomogenan varians dan keputusan ujian-t

\begin{tabular}{|c|c|c|c|c|c|c|c|}
\hline & \multicolumn{2}{|c|}{$\begin{array}{l}\text { Ujian Levene untuk } \\
\text { kehomogenan varians }\end{array}$} & \multicolumn{5}{|c|}{ Ujian-t untuk kesetaraan min } \\
\hline & \multirow[t]{2}{*}{$\mathbf{F}$} & \multirow[t]{2}{*}{ Sig, $p$} & \multirow[t]{2}{*}{$t$} & \multirow[t]{2}{*}{ df } & \multirow[t]{2}{*}{ Sig, p } & \multicolumn{2}{|c|}{$\begin{array}{c}\text { Perbezaan } 95 \% \text { selang } \\
\text { keyakinan }\end{array}$} \\
\hline & & & & & & Had bawah & Had atas \\
\hline Ujian pra & 0.062 & 0.803 & -0.722 & 90 & 0.472 & -12.450 & 5.813 \\
\hline Ujian pasca & 0.053 & 0.818 & 2.100 & 90 & 0.038 & 0.551 & 19.802 \\
\hline
\end{tabular}

Ujian-t dua sampel tidak bersandar digunakan untuk menentukan perbezaan min skor ujian pra dan ujian pasca bagi kedua-dua kumpulan iaitu kumpulan eksperimen dan kumpulan kawalan. Melalui Jadual 7, kajian mendapati bahawa tidak terdapat perbezaan yang signifikan pada min skor ujian pra antara pelajar daripada kumpulan eksperimen $(\min =55.17, \mathrm{sp}=21.90)$ dengan pelajar daripada kumpulan kawalan $(\min =58.49, \mathrm{sp}=22.18) ; \mathrm{t}(90)=-0.72 ; \mathrm{p}>0.05[95 \% \mathrm{CI}=-12.45$ hingga 5.81]. Walau bagaimanapun, terdapat perbezaan yang signifikan pada min skor ujian pasca antara pelajar daripada kumpulan eksperimen $(\mathrm{min}=64.53, \mathrm{sp}=22.14)$ dengan pelajar daripada kumpulan kawalan $(\min =54.36, \mathrm{sp}=24.32) ; \mathrm{t}(90)=2.10 ; \mathrm{p}<0.05[95 \% \mathrm{CI}=0.55$ hingga 19.80].

Jadual 7: Perbandingan min skor ujian pra dan pasca bagi kumpulan eksperimen dan kawalan

\begin{tabular}{llccc}
\hline & Kumpulan & N & Min & Sisihan piawai \\
\hline Ujian pra & Eksperimen & 47 & 55.17 & 21.90 \\
& Kawalan & 45 & 58.49 & 22.18 \\
\hline Ujian pasca & Eksperimen & 47 & 64.53 & 22.14 \\
& Kawalan & 45 & 54.36 & 24.32 \\
\hline
\end{tabular}

Berdasarkan Jadual 8 didapati bahawa seramai 32 (68.09\%) orang responden dalam kumpulan eksperimen menunjukkan peningkatan, 9 (19.15\%) menunjukkan penurunan dan $6(12.77 \%)$ tidak menunjukkan sebarang perbezaan selepas penggunaan perisian GeoGebra. Manakala skor ujian pra dan ujian pasca bagi kumpulan kawalan menunjukkan peningkatan seramai $12(26.67 \%)$ orang responden, penurunan sebanyak $23(51.11 \%)$ dan tiada perbezaan seramai $10(22.22 \%)$ orang responden melalui pendekatan pengajaran konvensional.

Jadual 8: Frekuensi perbezaan skor ujian pra dan pasca bagi kumpulan eksperimen dan kawalan

\begin{tabular}{lcccccc}
\hline \multirow{2}{*}{ Kumpulan } & \multicolumn{5}{c}{ Perbezaan skor ujian pra dan pasca } \\
\cline { 2 - 7 } & \multicolumn{3}{c}{ Naik, } & \multicolumn{2}{c}{ Turun, $\downarrow$} & \multicolumn{2}{c}{ Tiada perbezaan, $\leftrightarrow$} \\
\cline { 2 - 7 } & $\mathbf{N}$ & $\mathbf{\%}$ & $\mathbf{N}$ & $\mathbf{\%}$ & $\mathbf{N}$ & $\boldsymbol{\%}$ \\
\hline Eksperimen & 32 & 68.09 & 9 & 19.15 & 6 & 12.77 \\
Kawalan & 12 & 26.67 & 23 & 51.11 & 10 & 22.22 \\
\hline
\end{tabular}

Hipotesis Nol 3: Tidak terdapat perbezaan yang signifikan min skor ujian pasca berdasarkan kategori pelajar kumpulan eksperimen selepas penggunaan perisian GeoGebra.

Jadual 9 menunjukkan bilangan responden mengikut prestasi iaitu rendah, sederhana dan tinggi berdasarkan gred yang diperoleh dalam subjek Matematik Tambahan Sijil Pelajaran Malaysia (SPM). Seramai $20(42.55 \%)$ orang responden dikategorikan di bawah prestasi rendah, $22(46.81 \%)$ orang responden berprestasi sederhana, manakala $5(10.64 \%)$ orang responden berprestasi tinggi. 
DOI: https://doi.org/10.47405/mjssh.v6i9.1035

Jadual 9: Data gred Matematik Tambahan SPM

\begin{tabular}{lccc}
\hline Gred Matematik Tambahan SPM & Prestasi & N & \% \\
\hline D dan E & Rendah & 20 & 42.55 \\
B+, B, C+ dan C & Sederhana & 22 & 46.81 \\
A+, A dan A- & Tinggi & 5 & 10.64 \\
\hline
\end{tabular}

Merujuk Jadual 10, pelajar berprestasi tinggi $(\min =86.80, \mathrm{sp}=14.03)$ mempunyai min skor yang tinggi dalam ujian pasca berbanding pelajar berprestasi sederhana $(\min =68.23, \mathrm{sp}=20.20)$ dan pelajar berprestasi rendah $(\min =54.90, \mathrm{sp}=21.23)$.

Jadual 10: Perbandingan min skor ujian selepas penggunaan perisian GeoGebra berdasarkan prestasi pelajar

\begin{tabular}{lccccc}
\hline \multirow{2}{*}{ Prestasi } & N & Min & Sisihan piawai & Minimum & Maksimum \\
\cline { 2 - 6 } & 20 & 54.90 & 21.23 & 13 & 100 \\
Rendah & 22 & 68.23 & 20.20 & 27 & 100 \\
Sederhana & 5 & 86.80 & 14.03 & 67 & 100 \\
Tinggi & 47 & 64.53 & 22.143 & 13 & 100 \\
\hline Jumlah & & & & & \\
\hline
\end{tabular}

Ujian ANOVA satu hala telah dijalankan untuk melihat perbezaan min skor ujian pasca selepas penggunaan perisian GeoGebra antara pelajar berprestasi rendah, sederhana dan tinggi ini. Sebelum ujian tersebut digunakan, andaian normaliti data dan kehomogenan varians perlulah dipenuhi. Jadual 11 menunjukkan dapatan bagi ujian normaliti. Oleh kerana $n<50$, maka ujian normaliti Shapiro-Wilk digunakan (Nor Aishah et al., 2011). Keputusan aras signifikan bagi skor ujian pasca menunjukkan $\mathrm{p}>0.05$, maka data bertaburan secara normal.

Jadual 11: Ujian normaliti data

\begin{tabular}{|c|c|c|c|c|c|c|c|}
\hline & \multirow[t]{2}{*}{ Kumpulan } & \multicolumn{3}{|c|}{ Kolmogorov-Smirnov ${ }^{a}$} & \multicolumn{3}{|c|}{ Shapiro-Wilk } \\
\hline & & Statistik & df & Sig, p & Statistik & df & Sig, $p$ \\
\hline Ujian pasca & Eksperimen & 0.103 & 47 & 0.200 & 0.964 & 47 & 0.162 \\
\hline
\end{tabular}

Keputusan ujian Levene dalam Jadual 12, $\mathrm{F}(2,44)=0.551 ; \mathrm{p}>0.05$ menunjukkan bahawa ia tidak signifikan. Ini bermakna nilai varians pemboleh ubah bersandar dalam setiap kumpulan pelajar berdasarkan prestasi adalah hampir sama dan ini memenuhi syarat ujian ANOVA.

Jadual 12: Ujian kehomogenan varians

\begin{tabular}{lccc}
\hline Statistik Levene & df1 & df2 & Signifikan \\
\hline 0.551 & 2 & 44 & 0.580 \\
\hline
\end{tabular}

Dapatan ujian ANOVA satu hala dalam Jadual 13 mendapati bahawa terdapat perbezaan yang signifikan antara skor ujian pasca antara ketiga-tiga kumpulan prestasi pelajar iaitu prestasi rendah, sederhana dan tinggi iaitu $\mathrm{F}(2,44)=5.691 ; \mathrm{p}<0.05, \eta^{2}=0.206$. Nilai effect size analisis ini $\left(\eta^{2}=0.206\right)$ adalah melebihi anggaran Cohen (1988) bagi kesan yang besar. Ini bermakna perbezaan prestasi pelajar mempengaruhi pencapaian dalam ujian pasca. Berdasarkan analisis post-hoc Tukey dalam Jadual 14 pula didapati bahawa terdapat perbezaan signifikan antara pelajar berprestasi rendah dan pelajar berprestasi tinggi. Namun, tidak terdapat perbezaan yang signifikan antara pelajar berprestasi rendah dan sederhana begitu juga dengan pelajar berprestasi sederhana dan tinggi. 
DOI: https://doi.org/10.47405/mjssh.v6i9.1035

Jadual 13: Ujian ANOVA bagi ujian pasca berdasarkan prestasi pelajar

\begin{tabular}{lccccc}
\hline Prestasi pelajar & Jumlah kuasa dua & df & Min kuasa dua & Nilai F & Sig, p \\
\hline Antara kumpulan & 4635.238 & 2 & 2317.619 & 5.691 & 0.006 \\
Dalam kumpulan & 17918.464 & 44 & 407.238 & & \\
\hline Jumlah & 22553.702 & 46 & & & \\
\hline
\end{tabular}

Jadual 14: Ujian post-hoc Tukey HSD

\begin{tabular}{llccccc}
\hline (I) & $(\mathbf{J})$ & Perbezaan & \multirow{2}{*}{ Ralat piawai } & \multirow{2}{*}{ Signifikan } & \multicolumn{2}{c}{ 95\% selang keyakinan } \\
\cline { 6 - 7 } Prestasi & Prestasi & min $(\mathbf{I}-\mathbf{J})$ & & & Had bawah & Had atas \\
\hline Rendah & Sederhana & -13.327 & 6.235 & 0.094 & -28.45 & 1.80 \\
& Tinggi & $-31.900^{*}$ & 10.090 & 0.008 & -56.37 & -7.43 \\
\hline \multirow{2}{*}{ Sederhana } & Rendah & 13.327 & 6.235 & 0.094 & -1.80 & 28.45 \\
& Tinggi & -18.573 & 9.998 & 0.163 & -42.82 & 5.68 \\
\hline \multirow{2}{*}{ Tinggi } & Rendah & $31.900^{*}$ & 10.090 & 0.008 & 7.43 & 56.37 \\
& Sederhana & 18.573 & 9.998 & 0.163 & -5.68 & 42.82 \\
\hline
\end{tabular}

*. Perbezaan min adalah siginifikan pada kedudukan 0.05

Merujuk Jadual 15 didapati bahawa seramai 15 (75.00\%) orang responden dalam kumpulan pelajar berprestasi rendah menunjukkan peningkatan dan 5 (25.00\%) orang responden menunjukkan penurunan skor ujian selepas penggunaan perisian GeoGebra. Pelajar berprestasi sederhana pula menunjukkan peningkatan seramai 14 (63.64\%) orang responden, penurunan skor ujian pasca dan tiada perbezaan antara skor ujian pra dan pasca kedua-duanya menunjukkan seramai 4 (18.18\%) orang responden. Bagi pelajar berprestasi tinggi pula, seramai $3(60.00 \%)$ orang responden menunjukkan peningkatan dan $2(40.00 \%)$ pula tiada perbezaan antara skor ujian pra dan pasca.

Jadual 15: Frekuensi perbezaan skor ujian pra dan ujian pasca bagi pelajar berprestasi rendah, sederhana dan tinggi

\begin{tabular}{lcccccc}
\hline \multirow{3}{*}{ Prestasi } & \multicolumn{6}{c}{ Perbezaan skor ujian pra dan pasca } \\
\cline { 2 - 7 } & \multicolumn{2}{c}{ Naik, $\uparrow$} & \multicolumn{2}{c}{ Turun, $\downarrow$} & \multicolumn{2}{c}{ Tiada perbezaan, $\leftrightarrow$} \\
\cline { 2 - 7 } & $\mathbf{N}$ & $\mathbf{N}$ & \% & N & $\%$ \\
\hline Rendah & 15 & 75.00 & 5 & 25.00 & 0 & 0.00 \\
Sederhana & 14 & 63.64 & 4 & 18.18 & 4 & 18.18 \\
Tinggi & 3 & 60.00 & 0 & 0.00 & 2 & 40.00 \\
\hline
\end{tabular}

\section{Analisis Tahap Keberkesanan Penggunaan Perisian Matematik (GeoGebra) dalam Pengajaran dan Pembelajaran Topik Fungsi dan Graf}

Terdapat tiga konstruk dalam soal selidik yang telah diedarkan kepada kumpulan eksperimen yang bertujuan untuk menilai tahap keberkesanan penggunaan perisian matematik (GeoGebra) dalam pengajaran dan pembelajaran topik fungsi dan graf. Analisis yang diperolehi adalah seperti dalam Jadual 16.

Jadual 16: Analisis tahap keberkesanan penggunaan perisian matematik (GeoGebra) dalam pengajaran dan pembelajaran topik fungsi dan graf mengikut konstruk

\begin{tabular}{lcc}
\hline Konstruk & Min & Interpretasi \\
\hline $\begin{array}{l}\text { Pengajaran dan pembelajaran matematik } \\
\text { Penggunaan perisian matematik dalam pengajaran matematik }\end{array}$ & 4.25 & Tinggi \\
$\begin{array}{l}\text { Keberkesanan GeoGebra sebagai bahan bantu mengajar dalam topik } \\
\text { fungsi dan graf }\end{array}$ & 3.40 & Sederhana \\
\hline Keseluruhan & & Tinggi \\
\hline \multicolumn{1}{c}{ www.msocialsciences.com } & & Tinggi \\
\hline
\end{tabular}


Secara keseluruhannya, 68.09\% responden bersetuju bahawa mereka tidak menghadapi masalah untuk mempelajari matematik dengan menggunakan perisian matematik. $100 \%$ responden sangat bersetuju bahawa perisian GeoGebra dapat membantu responden untuk memahami graf dengan lebih baik serta mengenalpasti pelbagai bentuk graf. 59.57\% responden pula bersetuju bahawa mempelajari topik fungsi menjadi lebih mudah dengan menggunakan perisian GeoGebra. Namun begitu, $74.47 \%$ responden sangat bersetuju bahawa responden dapat memahami matematik dengan baik apabila pensyarah menunjukkan cara untuk menyelesaikannya. Selain itu, $55.32 \%$ responden sangat bersetuju agar penjelasan diberi terlebih dahulu oleh pensyarah sebelum responden memahami sesuatu konsep dalam matematik. Ini bermakna, walaupun perisian GeoGebra menjadi suatu alat bantu mengajar yang banyak membantu dalam proses pengajaran dan pembelajaran, namun pendedahan awal mengenai konsep sesuatu topik dalam matematik itu perlu dijelaskan dahulu oleh guru terutamanya tajuk-tajuk yang sukar seperti fungsi dan graf ini.

\section{Perbincangan Kajian}

\section{Pencapaian pelajar sebelum dan selepas penggunaan perisian GeoGebra}

Dapatan kajian menunjukkan tidak terdapat perbezaan yang signifikan pada min skor ujian pra antara pelajar daripada kumpulan eksperimen dengan kumpulan kawalan. Ini selari dengan kajian yang telah dijalankan oleh Zengin dan Tatar (2017), Bayaga et al. (2019) dan Chalaune dan Subedi (2020). Hasil dapatan ini menunjukkan bahawa pada peringkat permulaan kajian, pelajar dalam kumpulan eksperimen dan kumpulan kawalan mempunyai kebolehan yang setara dalam mata pelajaran matematik. Sebelum perisian GeoGebra diperkenalkan, pelajar-pelajar ini telah terdedah dengan konsep asas beberapa fungsi graf semasa di peringkat sekolah. Namun konsep ini diperkenalkan dengan pendekatan konvensional dan pelajar memilih untuk mengingat bentuk-bentuk graf berbanding memahami konsepnya.

Berdasarkan ujian pasca pula didapati terdapat perbezaan yang signifikan pada min skor antara pelajar daripada kumpulan eksperimen dengan pelajar daripada kumpulan kawalan. Ini menunjukkan penggunaan perisian GeoGebra adalah lebih baik berbanding pengajaran menggunakan kaedah konvensional. Selain itu, kajian ini turut membuktikan pencapaian pelajar meningkat selepas penggunaan perisian GeoGebra. Keputusan yang diperoleh ini menyokong kajian yang dilaksanakan oleh Zengin dan Tatar (2017), Otieno et al. (2017) dan Chalaune dan Subedi (2020). Seterusnya, pengkaji ingin mengenal pasti sama ada terdapat perbezaan atau tidak berdasarkan kategori pelajar yang berada dalam kumpulan eksperimen. Pengkaji dapati terdapat perbezaan yang signifikan antara skor ujian pasca antara ketiga-tiga kumpulan prestasi pelajar iaitu prestasi rendah, sederhana dan tinggi melalui ujian ANOVA satu hala. Menerusi analisis pos hoc Tukey, didapati bahawa terdapat perbezaan signifikan antara pelajar berprestasi rendah dan pelajar berprestasi tinggi. Namun, tidak terdapat perbezaan yang signifikan antara pelajar berprestasi sederhana dengan dua kumpulan yang lain. Ini bermakna pelajar berprestasi tinggi mendapat skor yang lebih tinggi berbanding pelajar berprestasi rendah selepas penggunaan perisian GeoGebra. Pengkaji berpendapat walaupun perisian GeoGebra ini dapat dijadikan sebagai alternatif dalam proses pengajaran, namun pelajar-pelajar yang berprestasi rendah masih memerlukan bimbingan secara terus daripada pensyarah di samping penggunaan perisian GeoGebra ini.

Pengkaji mendapati melalui pendekatan konvensional, ramai pelajar akan menunggu pensyarah untuk menunjukkan hasil graf yang diperoleh sekiranya diberikan sesuatu fungsi graf. Namun, pengkaji dapat melihat perbezaan bagi pelajar-pelajar yang terdedah dengan perisian GeoGebra (kumpulan eksperimen) ini. Pelajar akan cuba untuk mengeksplorasi perisian GeoGebra apabila sesuatu fungsi graf diberikan oleh pensyarah. Ini secara tidak langsung pembelajaran akses kendiri dapat diterapkan dalam diri pelajar. Walau bagaimanapun, pelajar agak sukar memahami dan melakar graf bagi fungsi cebis demi cebis (piecewise function). Ini disebabkan fungsi ini melibatkan beberapa fungsi berserta syarat untuk nilai $x$ yang perlu memenuhi fungsi berkenaan. Pengkaji berpendapat agak sukar untuk membuat perbandingan dengan kajian-kajian lain kerana kebanyakan kajian yang dijalankan tertumpu 
kepada satu jenis fungsi graf sahaja. Antaranya adalah fungsi linear (Soots \& Shafer, 2018; Joshi \& Singh, 2020), fungsi kuadratik (Ovez, 2018; Fatahillah et al., 2020) atau fungsi nilai mutlak (Gono, 2016; Widjajanti, 2019).

\section{Keberkesanan penggunaan perisian GeoGebra dalam pengajaran dan pembelajaran topik fungsi dan graf}

Secara keseluruhannya, responden sangat bersetuju bahawa penggunaan perisian GeoGebra dalam tajuk fungsi dan graf dapat membantu responden untuk mengenal pasti pelbagai bentuk graf serta memahami graf dengan lebih baik. Ini selari dengan kajian Nobre et al. (2016) yang menyatakan bahawa penggunaan GeoGebra mampu meningkatkan kemahiran visualisasi pelajar. Responden turut tidak menghadapi masalah untuk mempelajari matematik dengan menggunakan perisian matematik dan merasakan pembelajaran topik fungsi menjadi lebih mudah dengan menggunakan perisian GeoGebra. Responden bersetuju bahawa pembelajaran graf jadi lebih menarik apabila menggunakan perisian GeoGebra berbanding penerangan daripada pensyarah sahaja. Ini bermakna, melalui penggunaan perisian GeoGebra, proses pengajaran dan pembelajaran menjadi lebih menarik (Mudaly \& Fletcher, 2019) serta menggalakkan penerokaan kendiri oleh pelajar sendiri (Nazihatulhasanah \& Nurbiha, 2015).

Dapatan kajian ini juga menunjukkan kemahiran visualisasi pelajar yang terdedah kepada GeoGebra secara tidak langsung semakin baik. Pelajar dapat melihat perubahan parameter sesuatu fungsi graf akan menyebabkan perubahan pada bentuk graf melalui penggunaan perisian GeoGebra. Sebagai contoh, secara umumnya pelajar mengetahui bahawa bentuk umum bagi persamaan kuadratik adalah $a x^{2}+b x+c=0$, namun terdapat sebilangan pelajar yang tidak menyedari bahawa perubahan nilai pada parameter a sama ada bernilai positif dan negatif itulah yang sebenarnya yang menyebabkan perubahan pada bentuk graf. Sekiranya semakin kerap pelajar terdedah dengan penggunaan perisian GeoGebra ini, pelajar akan lebih memahami konsep fungsi dan graf yang selama dirasakan agak abstrak untuk digambarkan. Hal ini turut diakui oleh Joki'c dan Taka ci (2020) yang mengatakan bahawa pelajar yang kerap berlatih menggunakan perisian GeoGebra akan lebih memahami transformasi sesuatu fungsi. Namun demikian, responden sangat bersetuju agar penjelasan diberi terlebih dahulu oleh pensyarah sebelum responden memahami sesuatu konsep dalam matematik dan dapat memahami matematik dengan lebih baik apabila pensyarah menunjukkan cara untuk menyelesaikannya. Ini menunjukkan bahawa walaupun perisian GeoGebra banyak manfaatnya dalam sesi pengajaran dan pembelajaran, namun pendedahan awal mengenai konsep sesuatu topik dalam matematik itu perlu dijelaskan dahulu oleh pensyarah terutamanya tajuk-tajuk yang sukar seperti fungsi dan graf ini.

Berdasarkan item ketiga iaitu "Perisian GeoGebra membantu saya untuk mengenalpasti pelbagai bentuk graf" dan item keempat, "Perisian GeoGebra membantu saya untuk memahami graf dengan lebih baik", 100\% responden sangat bersetuju dengan kedua-dua pernyataan ini. Hal ini kerana responden merasakan mereka dapat meneroka sendiri pelbagai bentuk graf melalui perisian GeoGebra. Pelajar lebih berdikari serta memahami ciri-ciri graf dan membuat visualisasi graf yang dipelajari tanpa perlu sentiasa merujuk kepada pensyarah. GeoGebra merupakan perisian yang dapat meningkatkan kualiti pembelajaran terutamanya untuk meneroka, membuat visualisasi, dan membina konsep matematik (Tamam \& Dasari, 2021). Nor Adibah et al. (2020) pula menyatakan bahawa penggunaan perisian GeoGebra dalam proses pengajaran dan pembelajaran sangat membantu pelajar. Justeru, responden merasakan GeoGebra merupakan salah satu medium yang sangat efektif selain mendapat input daripada pensyarah semasa di dalam kelas. GeoGebra juga mudah untuk diakses sama ada melalui telefon pintar atau pun peranti lain seperti komputer riba dan sebagainya. Tambahan pula, perisian GeoGebra adalah percuma dan responden tidak perlu menggunakan talian internet selepas memuat turun perisian GeoGebra ke dalam komputer atau telefon pintar mereka. 


\section{Kesimpulan}

Melalui pelaksanaan kajian ini, pendidik akan lebih kreatif dalam mempelbagaikan kaedah pengajaran selari dengan trend semasa. Perkongsian bahan pengajaran para pendidik dari pelbagai negara di laman web GeoGebra dapat mewujudkan persekitaran pendidikan maya yang sentiasa berkembang dan juga membuka minda pendidik. Penggunaan GeoGebra sebagai medium penyampaian pengajaran di dalam kelas memberikan impak yang positif kepada pelajar. Pelajar merasai suatu pengalaman baru apabila didedahkan dengan sumber bahan pengajaran dan pembelajaran yang belum pernah diketahui sebelum ini. Penggunaan perisian GeoGebra ini juga telah banyak membantu pelajar terutamanya di luar waktu pengajaran dan pembelajaran. Ini secara tidak langsung, pembelajaran secara konstruktivisme dapat berlaku di mana seseorang pelajar itu menjadi individu yang aktif membina pengetahuannya sendiri dengan cara mengeksplorasinya. Penggunaan perisian GeoGebra sebagai bahan bantu mengajar sangat relevan dengan situasi pembelajaran masa kini yang kebanyakannya dilaksanakan secara dalam talian atau pun pembelajaran secara hibrid iaitu gabungan antara pembelajaran secara dalam talian dan bersemuka.

Berdasarkan dapatan dan batasan dalam kajian ini, terdapat beberapa cadangan untuk dikaji pada masa akan datang. Responden yang terlibat dalam kajian ini hanya terdiri daripada pelajar matrikulasi sahaja. Maka, hasil dapatan kajian ini tidak boleh digeneralisasikan untuk semua peringkat pengajian. Oleh itu, pengkaji mencadangkan agar kajian sebegini dapat didedahkan ke atas responden yang berbeza sama ada di peringkat sekolah rendah, menengah atau pun peringkat pengajian tinggi. Hal ini kerana perisian ini merangkumi pelbagai bidang dalam matematik serta memberi peluang kepada pendidik dan pelajar untuk meneroka dan membuat visualisasi bagi topik-topik matematik yang abstrak. Selain itu, pengkaji hanya berfokuskan kepada topik fungsi dan graf. Justeru, keberkesanan penggunaan perisian GeoGebra ini tertumpu kepada tajuk ini sahaja. Pengkaji lain yang bercadang untuk menggunakan perisian GeoGebra ini boleh juga mengaplikasikan dalam topik lain kerana perisian GeoGebra ini merupakan perisian matematik dinamik yang menggabungkan geometri, algebra, aritmetik, statistik, kalkulus, kebarangkalian, trigonometri dan fungsi. Terdapat juga pelbagai perisian matematik yang boleh digunakan dalam proses pengajaran dan pembelajaran; antaranya adalah Desmos, Maple, Geometer's Sketchpad dan Mathematica. Walau bagaimanapun, pengkaji mencadangkan agar pengkaji memilih perisian bersesuaian dengan topik yang diajar serta mengambil kira juga kebolehan responden dalam menggunakan perisian yang ada.

Kajian ini juga berfokus kepada penggunaan perisian GeoGebra dalam kalangan pelajar sahaja. Bagi memastikan sesuatu perisian matematik yang digunakan di dalam kelas itu efektif, pandangan serta kompetensi di pihak pendidik juga perlu diberi perhatian. Sehubungan itu, pengkaji mencadangkan agar terdapat kajian susulan yang mengkaji kemahiran penggunaan perisian GeoGebra dalam kalangan pengajar. Pihak Kementerian Pendidikan Malaysia (KPM) juga seharusnya memberi pendedahan yang lebih luas kepada para pendidik terutamanya dalam pendedahan bahan bantu mengajar berbentuk perisian memandangkan proses pengajaran dan pembelajaran sekarang lebih banyak tertumpu secara atas talian.

Kajian ini telah menjawab semua persoalan kajian yang ingin dikaji. Semua objektif yang dinyatakan pada awal kajian telah tercapai. Maklum balas responden juga menunjukkan kesan positif terhadap penggunaan perisian GeoGebra dalam pembelajaran fungsi dan graf. Secara umumnya, dapatlah dirumuskan bahawa perisian GeoGebra boleh dijadikan sebagai salah satu alternatif dalam pengajaran matematik untuk meningkatkan pencapaian pelajar. Walaupun terdapat banyak kajian telah dijalankan mengenai perisian GeoGebra, namun banyak lagi yang boleh diterokai melalui penggunaan perisian ini. Perkongsian bahan pengajaran para pendidik dari pelbagai negara di laman web GeoGebra juga dapat membuka minda kita selain menjadikan GeoGebra ini sebagai medium penyampaian pengajaran di dalam kelas. Melalui hasil dapatan kajian ini, adalah diharapkan bahawa kajian ini dapat membantu warga pendidik untuk memperbaiki taraf dan kualiti amalan pendidikan yang sistematik dan proaktif serta menjadi rujukan kepada warga pendidik matematik yang berminat untuk menggunakan perisian GeoGebra dalam proses pengajaran dan pembelajaran matematik. 


\section{Rujukan}

Abdul Halim, A., Sharifah Nurarfah, S.A.R. \& Mohd Hilmi, H. (2017). Metacognitive skills of Malaysian students in non-routine mathematical problem solving. Bolema Boletim de Educação Matemática, 31(57), 310-322.

Allanson, P.E. \& Notar, C.E. (2020). Statistics as measurement: 4 scales/levels of measurement. Education Quarterly Reviews, 3(3), 375-385.

Aw Yang Ai Shin \& Jenny Ku Fui Ling. (2017). Teknik DAIS: Satu kaedah pembelajaran untuk meningkatkan kemahiran melakar graf fungsi eksponen dan logaritma. Journal of Science and Mathematics Letters, 5, 63-72.

Birgin, O., \& Acar, H. (2020). The effect of computer-supported collaborative learning using GeoGebra software on 11th grade students' mathematics achievement in exponential and logarithmic functions. International Journal of Mathematical Education in Science and Technology, 1-18.

Brown, F.L., Farag, A.I., Abd Alla, F.H., Radford, K., Miller, L., Neijenhuijs, K., Stubbé, H., de Hoop, T., Abbadi, A.A., Turner, J.S., Jetten, A. \& Jordans, M.J.D. (2020). Can't wait to learn: a quasi-experimental mixed-methods evaluation of a digital game-based learning programme for out-of-school children in Sudan. Journal of Development Effectiveness, 1-22.

Carnaúba, F. \& Blikstein, P. (2020). The use of GeoGebra in Brazil from a constructionist perspective. Proceedings of the 2020 Constructionism Conference, 112-113.

Casey, B.M \& Fell, H. (2019). Spatial reasoning: a critical problem-solving tool in children's mathematics strategy tool kit. In Mix, K.S \& Battista, M.T. (Eds.). Visualizing mathematics: the role of spatial reasoning in mathematical thought. (pp. 47-164). Switzerland: Springer.

Chalaune, B.B. \& Subedi, A. (2020). Effectiveness of GeoGebra in teaching school mathematics. Contemporary Research: An Interdisciplinary Academic Journal, 4(1), 46-58.

Cohen, J. (1988). Statistical Power Analysis for The Behavioral Sciences Second Edition. New York: Lawrence Erlbaum Associates.

Dahal, N., Shrestha, D. \& Pant, B.P. (2019). Integration of GeoGebra in teaching and learning geometric transformation. Journal of Mathematics and Statistical Science, 5, 323-332.

Effandi, Z, Md. Yusoff, D \& Norazah, M.N. (2007). Teknologi dalam pengajaran dan pembelajaran matematik. Dlm. Effandi Zakaria, Norazah Mohd Nordin \& Sabri Ahmad (Eds.). Trend Pengajaran dan Pembelajaran Matematik. (pp. 51-66). Kuala Lumpur: Utusan Publications \& Distributors Sdn. Bhd.

Fatahillah, A., Puspitasari, I.D. \& Hussen, S. (2020). The development of Schoology web-based learning media with GeoGebra to improve the ICT literacy on quadratic functions. Journal of Research and Advances in Mathematics Education, 5(3), 304-316.

Furner, J.M. \& Yahya, N. (2020). Using GeoGebra, photography and vocabulary to teach mathematics while aiding our ESOL populations. Transformations, 6(1), 19-41.

Gono, E.N. (2016). The contributions of Interactive Dynamic Mathematics software in probing understanding of mathematical concepts: Case study on the use GeoGebra in learning the concept of modulus functions. Doctoral thesis, UCL (University College London).

Hadjichambis, A.C. \& Paraskeva-Hadjichambi, D. (2020). Environmental citizenship questionnaire (ECQ): the development and validation of an evaluation instrument for secondary school students. Sustainability, 12(3), 1-12.

Hutkemri \& Effandi, Z. (2012). The effect of Geogebra on students' conceptual and procedural knowledge of function. Journal of Science and Technology, 5(12), 104-110.

Johnson, R.B \& Christensen, L. (2014). Educational Research: Quantitative, Qualitative, And Mixed Approaches. California: SAGE Publications, Inc.

Joki'c, M. \& Taka ci, U. (2020). Efficiency of dynamic computer environment in learning absolute value equation. Symmetry, 2020 12(3), 473-493.

Joshi, D.R. \& Singh, K.B. (2020). Effect of using Geogebra on eight grade students' understanding in learning linear equations. Mathematics Teaching Research Journal, 12(3), 76-83.

Kementerian Pendidikan Malaysia. (2013). Pelan Pembangunan Pendidikan Malaysia 2013-2025 (Pendidikan Prasekolah hingga Lepas Menengah). Putrajaya: Kementerian Pendidikan Malaysia. 
Khalil, M., Khalil, U. \& Haq, Z.U. (2019). GeoGebra as a scaffolding tool for exploring analytic geometry structure and developing mathematical thinking of diverse achievers. International Electronic Journal of Mathematics Education, 14(2), 427-434.

Khor, M.K. \& Ruzlan, M.A. (2017). GeoGebra: towards realizing 21st century learning in mathematics education. Malaysian Journal of Learning and Instruction: Special Issues, 93-115.

Leong, K.W. (2015). The effects of instruction using the ARCS model and GeoGebra on upper secondary students' motivation and achievement in learning combined transformation. Asia Pacific Journal of Educators and Education, 30, 141-158.

Miller, C.J., Smith, S.N. \& Pugatch, M. (2020). Experimental and quasi-experimental designs in implementation research. Psychiatry Research, 283, 1-7.

Mohd. Majid Konting. (2005). Kaedah Penyelidikan Pendidikan. Kuala Lumpur: Dewan Bahasa dan Pustaka.

Moreno-Guerrero, A.J., Aznar-Díaz, I., Cáceres-Reche, P. \& Alonso-García, S. (2020). E-learning in the teaching of mathematics: an educational experience in adult high school. Mathematics 2020, 8 (840), 1-16.

Mudaly, V. \& Fletcher, T. (2019). The effectiveness of GeoGebra when teaching linear functions using the Ipad. Problems of Education in the 21st Century, 77(1), 55-81.

Murni, V., Sariyasa, S. \& Ardana I.M. (2017). GeoGebra assist discovery learning model for problem solving ability and attitude toward mathematics. Journal of Physics: Conference Series 895.

Mushipe, M. \& Ogbonnaya, U.I. (2019). GeoGebra and grade 9 learners' achievement in linear functions. International Journal of Engineering and Technology (IJET), 14(8), 206-219.

Nazihatulhasanah Arbain \& Nurbiha A. Shukor. (2015). The effects of GeoGebra on students achievement. Procedia - Social and Behavioral Sciences 172, 208-214.

Nobre, C.N, Meireles, M.R.G, Junior, N.V, Resende, M.N, Costa, L.E \& Rocha, R.C. (2016). The use of geogebra software as a calculus teaching and learning tool. Informatics in Education 15(2), 253-267.

Nor Adibah Abdullah, Nur E'zzatul Hamizah Mukhtar, Nurzarina Amran. (2020). Persepsi pelajar terhadap pembelajaran berasaskan perisian matematik. Sains Humanika 12(3), 1-8.

Nor Aishah, A, Teh, S.Y., Abdul Rahman, O. \& Che Rohani, Y. (2011). Sensitivity of Normality Tests to Non-normal Data. Sains Malaysiana, 40(6), 637-641.

Ogan, C. \& Ibibo, G. (2018). GeoGebra: a technological software for teaching and learning of calculus in Nigerian schools. American Journal of Applied Mathematics and Statistics, 6(3), 115-120.

Otieno, O.H., Owiti, D.S. \& Wanjala, M.M. (2017). GeoGebra instruction software and its effect on students' achievement in mathematics in secondary schools of Kakamega County, Kenya. International Journal of Interdisciplinary Research and Innovations, 5(4), 82-88.

Ovez, F.T.D. (2018). The impact of instructing quadratic functions with the use of GeoGebra software on students' achievement and level of reaching acquisitions. International Education Studies, $11(7)$.

Pfeiffer, C. (2017). A study of the development of mathematical knowledge in a GeoGebra-focused learning environment. Doctoral thesis, University of Stellenbosch.

Priwantoro, S.W. \& Fahmi, S. (2019). Development and effectiveness of GeoGebra based learning media reviewed from learning result and self confident. At-Taqaddum, 11(1), 1-27.

Rohaidah, M., Ting, S.H., Nor'ain, M.T., Zamzana, Z. \& Raja Lailatul Zuraida, R.M.S. (2016). The effects of using GeoGebra teaching strategy in Malaysian secondary schools: a case study from Sibu, Sarawak. GEOGRAFIA Online TM Malaysian Journal of Society and Space, 12(7), 13-25.

Saidatuna, M.J.A. \& Rosseni, D. (2016). Teaching and learning geometry using GeoGebra software via MOOC. GEOGRAFIA Online TM Malaysian Journal of Society and Space, 12(7), 13-25.

Septian, A., Sugiarni, R. \& Monariska, E. (2020). The application of Android-based GeoGebra on quadratic equations material toward mathematical creative thinking ability. Al-Jabar: Jurnal Pendidikan Matematika, 11(2), 261-272.

Shabiralyani, G., Hasan, K.S., Hamad, N. \& Iqbal, N. (2015). Impact of visual aids in enhancing the learning process case research: District Dera Ghazi Khan. Journal of Education and Practice, 6(19), 226-234.

Soots, K.L. \& Shafer, K.G. (2018). Engaging students with linear functions and GeoGebra: an action research study. North American GeoGebra Journal, 7(1), 53-70. 
Tamam, B. \& Dasari, D. (2021). The use of Geogebra software in teaching mathematics. Journal of Physics: Conference Series, 1882012042.

Widjajanti, K., Nusantara, T. As'ari, A.R., Irawati, S., Haris, Z.A., Akbar, D.N. \& Lusbiantoro, R. (2019). Delaying scaffolding using GeoGebra: improving the ability of Vocational students to draw conclusions. TEM Journal, 8(1), 305-310.

Zengin, Y. \& Tatar, E. (2017). Integrating dynamic mathematics software into cooperative learning environments in mathematics. Journal of Educational Technology \& Society, 20(2), 74-88. 